\title{
DEFININDO MINORIAS: DESAFIOS, TENTATIVAS E ESCOLHAS PARA SE ESTABELECER CRITÉRIOS MÍNIMOS RUMO A CONCEITUAÇÃO DE GRUPOS MINORITÁRIOS
}

\author{
Rebeca Costa Gadelha da Silveira* \\ Raquel Coelho de Freitas ${ }^{* *}$
}

\section{RESUMO}

Como conceituar minorias? Embora pareça simples definir quem são as minorias, trata-se de temática complexa que invoca diversas divergências. Se por um lado adotar um conceito puramente objetivo excluiria determinados grupos notadamente minoritários, por outro a utilização de critérios subjetivos possibilitaria a prática de abusos e fraudes. Busca-se um ponto de equilíbrio de critérios para a definição de minorias. A metodologia utilizada na pesquisa é teórica e bibliográfica. Escolhe-se a discriminação como critério objetivo e a igualdade material redimensionada pela diferença como critério subjetivo. Utilizando-se dos critérios escolhidos, analisa-se se as pessoas com deficiência podem ser caracterizadas como grupos minoritários.

Palavras-chave: Conceito de Minorias. Critérios mínimos de definição. Discriminação como critério mínimo objetivo. Igualdade material redimensionada pela diferença como critério mínimo subjetivo. Pessoas com deficiência como minorias.

\section{DEFINING MINORITIES: CHALLENGES, ATTEMPTS AND CHOICES TO ESTABLISH MINIMUM CRITERIA TOWARD THE CONCEPT OF MINORITY GROUPS}

\footnotetext{
*Mestranda em Direito pela Universidade Federal do Ceará (UFC). Pós-Graduada em Direito do Trabalho e Processo do Trabalho pela Faculdade Entre Rios do Piauí (FAERPI). Graduada em Direito pelo Centro Universitário Christus (UNICHRISTUS). Técnica Ministerial no Ministério Público do Estado do Ceará (MPCE). Coordenadora discente do Grupo Arvore-ser "Grupo de Estudos Aplicados em Direito das Pessoas com Deficiência" da Faculdade de Direito da Universidade Federal do Ceará. Endereço postal: Avenida Beira Mar $n^{\circ}$ 4000, ap. 1500, bairro Meireles, Fortaleza/CE, CEP: 60.165-121. Endereço eletrônico: bekagadelhinha@hotmail.com

** Doutora em Direito Público pela Universidade do Estado do Rio de Janeiro (UERJ). Mestre em Direito Constitucional pela Harvard Law School. Especialista em Violência Urbana pela Universidade Federal de Pernambuco. Graduação em Direito pela Universidade Federal do Ceará (UFC). Professora associada a Universidade Federal do Estado do Ceará (UFC). Endereço postal: Avenida Rui Barbosa, nº 2111, ap. 201, bairro Joaquim Távora, Fortaleza/CE, CEP: 60115-222. Endereço eletrônico: rclcesar@gmail.com
} 


\begin{abstract}
How to conceptualize minorities? Although it seems simple to define it, it is a complex issue that lights up divergences. If adopting an objective concept of minorities would exclude certain minority group, on the other hand use only subjective criteria would lead to abuse. A point of equilibrium between objective and subjective criteria is sought. The methodology used is theoretical and bibliographical. Discrimination is chosen as the objective criteria and the subjective criterion is the material equality resized by the right of difference. Using the criteria chosen, it is analyzed whether people with disabilities can be characterized as minority group.
\end{abstract}

Keywords: Concept of minorities. Minimum criteria for definition. Discrimination as the minimum objective criteria. Material equality resized by the right of difference as the minimum subjective criteria. People with disabilities as minorities.

\title{
1. INTRODUÇÃO
}

Quem são as minorias? Existe uma definição absoluta sobre o que seriam os grupos minoritários? Nesta ordem, quais os principais elementos que seriam necessários para se definir quais grupos minoritários seriam assim caracterizados? O presente trabalho objetiva, num primeiro momento, definir quem são as minorias. Para tanto, explicam-se as definições tradicionais, em especial, a de Francesco Capotorti, na qual se preconizava principalmente critérios objetivos essencialmente numéricos para se conceituar minorias.

Nesse sentido, levando em consideração a insuficiência da definição clássica, na medida em que se excluíam certas minorias da proteção do artigo 27 do Pacto dos Direitos Civis e Políticos, surgiu a necessidade de ruptura com essa primeira tentativa de conceituar minorias, preferindo-se, neste ponto, definições que englobassem aspectos qualitativos, como, o contex to histórico, político e social, no qual a minoria está inserida ou a carência de representação política.

Todavia, a preferência por critérios exclusivamente subjetivos e a ampla abertura do conceito de minorias poderá dar margem a prática de abusos, excessos e fraudes, razão pela qual se impõe o estabelecimento de critérios mínimos para a formulação desta definição.

Diante da dificuldade de se estabelecer quem são as minorias, busca-se, em especial, o ponto ótimo entre um critério objetivo e um critério subjetivo, de tal forma que não se exclua nenhum grupo minoritário, mas, possa estar sempre aberto à inclusão de outros grupos que possam surgir posteriormente. 
Para atingir esses objetivos foi realizada pesquisa teórica e bibliográfica, compilandose os principais posicionamentos e documentos mais relevantes para a construção do conceito de minorias no decorrer do tempo, considerando-se ainda, neste ponto, a mudança do contexto social, político e econômico em que as minorias estiveram inseridas.

Por fim, utilizando-se dos critérios mínimos escolhidos, quais sejam, a discriminação e a igualdade material redimensionada pela diferença, será analisado se as pessoas com deficiência se encaixam ou não como grupo minoritários de modo a chamar para si a proteção inerente dos direitos das minorias.

\section{QUEM SÃO AS "MINORIAS"?}

O termo "minorias" suscita muitas dúvidas acerca de sua definição. Trata-se de tema complexo tanto numa seara doméstica como no âmbito internacional, havendo divergências entre os principais doutrinadores acerca do que seriam minorias e como se caracterizariam os grupos minoritários. Para se compreender o contexto no qual está inserida determinada minoria e a complexidade que a discussão possui, é preciso atentar para a diferença existente entre os seres humanos e as especificidades culturais, linguísticas, religiosas ou étnicas de cada Estado. Assim como não é possível a adoção de uma regra universal de justiça ou um ordenamento jurídico único para todas as Nações, as minorias também variam no tempo e no espaço.

Nesse sentido, não há como se desconsiderar a diferença e a complexidade que permeia os grupos humanos, devendo-se levar em consideração tais especificidades quando da formulação de um conceito de minorias. É possível, assim, que uma mesma minoria, a exemplo das pessoas com deficiência, possua tratamento, bem como desenvolvimento histórico, social, cultural ou político diferenciados a depender do Estado ou da comunidade a que pertençam, dificultando ainda mais o trabalho de quem deseja adotar um conceito ou definição do que são minorias.

Não obstante a dificuldade e os obstáculos encontrados no que tange a uma definição do termo e, consequentemente, como se caracterizariam os grupos minoritários, alguns doutrinadores arriscaram-se a elaborar e adotar uma definição de forma absoluta e definitiva. 
A concepção tradicional de minorias apresentada pelo professor Francesco Capotorti, a qual foi formulada como método interpretativo da proteção prevista no artigo 27 do Pacto dos Direitos Civis e Políticos ${ }^{1}$, limitou-se apenas a um critério quantitativo, essencialmente objetivo e científico, na medida em que delimitou minorias a um grupo numericamente inferior e não dominante.

A group numerically inferior to the rest of the population of a State, in a non-dominant position, whose members - being nationals of the State - possess ethnic, religious or linguistic characteristics differing from those of the rest of the population and show, if only implicitly, a sense of solidarity, directed, towards preserving their culture, traditions, religion or language. (CAPOTORTI apud NÓBREGA; JOCA, 2009, on line)

Observa-se que o conceito tracejado pelo autor elencou alguns elementos essenciais para a definição do que seria uma minoria, ressaltando-se, o critério numérico quando afirma se tratar de grupo numericamente inferior, o elemento da não dominância por estarem numa posição não dominante, da cidadania por necessariamente fazer parte do Estado e o elemento da solidariedade entre os membros da minoria no sentido de preservar a cultura, a tradição, a religião ou a linguagem daquele grupo.

Buscou-se, assim, um critério mais científico e fechado para a definição de minorias, não atentando o autor para elementos subjetivos propriamente ditos. A definição tradicional foi inclusive adotada pelo Tribunal Permanente de Justiça Internacional, o qual também acabou por rejeitar elementos subjetivos de definição de minorias. (PIRES apud WUCHER, 2000, p.48).

Com efeito, tendo em vista os elementos delineados na concepção tradicional, algumas críticas foram construídas a fim de aperfeiçoar a definição de minorias. Em primeiro lugar, minorias nem sempre são numericamente inferiores ao resto da população do Estado. $\mathrm{O}$ conceito exclusivamente quantitativo não abrange a essência do grupo, que se constitui no fator de discriminação que as inferioriza ou as descaracteriza em relação ao resto da população, ou

\footnotetext{
${ }^{1}$ Artigo 27 - Nos Estados em que haja minorias étnicas, religiosas ou lingüísticas, as pessoas pertencentes a essas minorias não poderão ser privadas do direito de ter, conjuntamente com outros membros de seu grupo, sua própria vida cultural, de professar e praticar sua própria religião e usar sua própria língua.
} 
seja, não atenta para critérios subjetivos essenciais e necessários para a complementação de uma definição do que seria minoria.

Em alguns casos não se trata necessariamente de um "grupo numericamente inferior". Mulheres, negros, idosos, crianças e adolescentes compõem atualmente número significativo da população mundial, razão pela qual não se encaixariam no critério quantitativo adotado tradicionalmente (ROCHA, 1999, p. 285).

O regime do apartheid ocorrido na África do Sul exemplifica um obstáculo ao elemento numérico, uma vez que a maioria negra daquele Estado ficou submetida ao regime discriminatório e segregativo imposto por uma minoria branca, o que, via de consequência, não ensejaria a proteção deste grupo nos moldes previstos no artigo 27 do Pacto dos Direitos Civis e Políticos (NOBREGA; JOCA, online).

Critica-se, ainda, a concepção tradicional no que tange ao elemento da cidadania, uma vez que, para uma pessoa ser considerada minoria e gozar da proteção destinada aos grupos minoritários pelos diplomas internacionais ou domésticos, não seria necessária vinculação natural ao Estado, sendo dele nacional ou naturalizado.

Limitar o termo "minorias" somente a cidadãos acaba por excluir outros grupos também carentes da proteção destinada a grupos minoritários, como os refugiados, trabalhadores migrantes ou indígenas, os quais, conforme traceja Thornberry, seriam protegidos por meio de legislações infraconstitucionais ou mesmo através de outros diplomas diferentes dos que preveem a proteção das minorias (THORNBERRY, 1991, p. 07).

No Estado brasileiro, a Constituição Federal Brasileira de 1988 prevê no artigo $5^{\circ}$, a igualdade perante a lei, vedando-se a discriminação de qualquer tipo de natureza, garantindo tanto aos brasileiros nacionais ou naturalizados como aos estrangeiros domiciliados e não domiciliados no Brasil a inviolabilidade do direito à vida, à liberdade, à igualdade, à segurança e à propriedade, incluindo-se, neste ponto, igual proteção aos direitos referentes aos grupos minoritários.

Destaca-se, por fim, que as minorias não se limitam somente àquelas pessoas que possuem diferenças étnicas, religiosas e linguísticas, na medida em que se estaria excluindo de tal definição grupos notadamente minoritários, como pessoas com deficiência, mulheres, idosos ou crianças (NOBREGA; JOCA, online). 
Percebe-se, assim, a insuficiência da definição tradicional proposta por Francesco Capotorti. Não obstante se tenha preferido naquele momento de influência moderna preconizar conceitos objetivos para a definição do que seriam os grupos minoritários, desconsiderou-se por completo a existência de elementos subjetivos, os quais seriam essenciais para o desenvolvimento e complementação deste conceito.

Com efeito, segue-se período de ruptura com a concepção tradicional, passando os autores a desenvolverem uma concepção de minorias, no qual se levam em consideração elementos tais como o sentimento de pertença a determinado grupo ou a auto-afirmação de identidade.

Ressalta-se que os critérios de auto-determinação não devem ser utilizados sem se observar atentamente as suas implicações e limitações, porquanto poderia ocorrer, com a adoção deste, fraudes e abusos no que tange a preservação e efetivação dos direitos das minorias. Como bem destaca Walter Claudius Rothenburg “[...] assim como não se pode ignorar a precedência do critério da auto-identificação, não se deve sobrevalorizá-lo, mas admitir, em casos extremos, sua infirmação" (ROTHENBURG, 2010, p. 459-460).

Dessa forma, considerando a diversidade dos grupos humanos existentes, alguns autores defendem uma definição de minorias atenta ao contexto social, histórico, político e econômico no qual determinada minoria estaria inserida. Para se definir minorias, devem-se levar em consideração as características e condições em que a pessoa ou grupo minoritário está imersa, ou seja, necessário seria atentar para um conceito prima facie qualitativo.

Passa-se a pensar minorias como "todo grupo humano excluído de algum direito pelo simples fato de constituir um grupo diferente do que foi estabelecido como padrão" (NOBREGA; JOCA, online) ou como "[...] movimentos sociais, estruturados em torno de um sistema de valores comuns, de um estilo de vida homogêneo, de um sentimento de identidade ou pertença coletivos, ou mesmo de uma experiência de marginalização" (SEMPRINI, 1999, p. 44).

Nessa linha, destaca-se ainda a definição tracejada por Luciana Nogueira e Priscylla Joca, segundo a qual se desenvolve um conceito de minorias atento à dificuldade enfrentada por estes grupos em ocupar posições de poder ou tomar decisões que possam influenciar nos rumos da sociedade, propondo, ao final, compreender minorias como movimentos sociais de 
reconhecimento da identidade e da diferença em prol de uma democracia plural e participativa (NOBREGA; JOCA, online).

Por outro lado, Rios Júnior propõe a abertura do conceito de minorias, uma vez que "a frieza de uma definição escrita de minorias poderia gerar a exclusão de determinados grupos e pessoas que também mereceriam proteção especial” (RIOS JÚNIOR, 2012, p. 19), de modo a possibilitar a sua revisão quando os conceitos anteriormente adotados não mais subsistirem a realidade de determinado grupo minoritário (RIOS JÚNIOR, 2012, p. 24-25).

Dessa forma, a definição de minorias consistiria numa construção baseada no contexto social, político ou econômico em que está inserida e nas particularidades encontradas nos grupos minoritários, podendo ser revistas a qualquer momento, de modo a evitar a exclusão de determinados grupos minoritários e incluir posteriormente outros que venham a surgir. Tratase, assim, de um conceito não estanque, mas aberto a novas realidades e a mudanças com o decorrer do tempo.

Não obstante se trate a abertura do conceito de minorias de uma possibilidade viável, principalmente tendo em vista que o conhecimento humano se constitui de saberes provisórios que são aprimorados, retificados ou modificados constantemente, entende-se ser necessária a delimitação de critérios mínimos ou limites conceituais para uma definição de quem seriam os grupos minoritários, ou seja, quem seriam essas minorias, principalmente, a fim de se evitar abusos, excessos ou a adoção de posições meramente relativistas ou dominantes de um ponto de vista sobre o outro.

Propõe-se, assim, observar as minorias tendo em vista um ponto ótimo entre critérios objetivos e subjetivos para a sua definição com o intuito de equilibrar a delimitação de elementos, não excluindo, assim, determinados grupos da proteção minoritária e possa estar aberto a novas realidades e novas minorias que venham a surgir com o passar do tempo.

Uma definição adequada do que seriam minorias deve ser buscada em direitos, sentimentos e crenças comuns ao homem, um caminho médio, uma ponte de interseção entre as diferentes e distantes ilhas humanas; algo que todos almejam e seja intrínseca a natureza de ser humano, mas que poucos, de fato, alcançam.

Para tanto, considerando a insuficiência do elemento numérico proposto por Capotorti, foi eleito como critério objetivo, no presente trabalho, o sentimento de discriminação sofrido por grupos minoritários, entendendo-se como uma característica comum desses grupos, uma 
vez que a maioria possui relatos ou parte de sua história de reconhecimento de direitos relacionada à exclusão, ao extermínio, ou a preconceitos.

Como critério subjetivo, não obstante se reconheça a liberdade e a democracia como importantes fatores para a definição e complementação do conceito de minorias, será trabalhada, neste ponto, a noção da igualdade material redimensionada pela diferença.

\section{CRITÉRIOS MÍNIMOS PARA A DEFINIÇÃO DE MINORIAS}

Conforme foi destacado, embora um conceito aberto de minorias seja adequado, é importante delinear critérios mínimos para a conceituação de grupos minoritários em prol da construção de um significado que desenvolva a participação pluralística, a democracia, a liberdade, a igualdade, além de possibilitar o reconhecimento da identidade dos grupos minoritários, evitando-se, assim, a prática de fraudes, abusos e excessos.

Não se pode negar, assim, a necessidade de elaboração de critérios e direitos mínimos que os Estados devem observar para a consecução dos chamados "direitos das minorias", especialmente dos "direitos humanos das minorias".

Indaga-se, portanto, quais seriam esses critérios?

\subsection{A discriminação como critério objetivo mínimo.}

Elege-se como critério objetivo mínimo a discriminação sofrida pelos grupos minoritários no caminhar pela conquista de direitos e o reconhecimento de sua condição como parte integrante da sociedade como um todo. Em algum sentido, várias pessoas já sofreram discriminação, ocorrendo de tal prática remeter aos primórdios da Humanidade, como delineia Vital Moreira e Carla Marcelino Gomes (MOREIRA; GOMES, online).

A discriminação é condição que nasce com a formação do Brasil, país que se serviu da mão de obra escrava, primeiramente a indígena para depois transferi-la aos negros, os quais auxiliaram submissamente no desenvolvimento econômico do Estado, permanecendo ainda nos 
dias atuais, não obstante a Constituição Federal de 1988 vedar expressamente qualquer tipo de discriminação negativa e repressora de direitos.

O Brasil é, essencialmente, preconceituoso para com os seus próprios, de maneira que é possível se verificar a segregação existente entre diversas classes e a dicotomia entre diversos grupos constituídos em discriminações de sistemas binários: rico e pobre, negro e branco, índios e brancos, pessoas com deficiência e pessoas sem deficiência, surdos e ouvintes, dentre outros.

\section{Todavia, impõe-se definir, primeiramente, o que é discriminação.}

Discriminar implica a noção de segregar, negar direitos injustificadamente, de diminuir a condição de ser humano de uma determinada pessoa pelo simples fato de pertencer a grupos diferentes dos denominados normais ou dominantes. Discriminar é tratar ao seu semelhante de forma preconceituosa, não igualitária, injusta, desproporcional e não democrática. É negar a condição de humanidade e de dignidade, destacando-se, neste ponto, a definição tracejada por Jamile Coelho Moreno, segundo a qual a "Discriminação é a prática de ato de distinção contra pessoa do qual resulta desigualdade e injustiça, [...] Discriminar é excluir, negar cidadania e, via de consequência, a própria democracia.” (MORENO, 2009, p. 144).

Nesse sentido, Bobbio entende que a discriminação se constitui num juízo ulterior de valor, no qual um grupo classifica o outro como bom ou mau, ou seja, adota um juízo axiológico para caracterizar negativamente determinado indivíduo ou grupo de pessoas (BOBBIO, 2002, p. 108-109).

Desta forma, a discriminação poderia ser vista, ainda, conforme delineado por Brito Filho, num contexto de sujeição praticada por um sujeito ativo e subordinação ou discriminação sofrida por um sujeito passivo (BRITO FILHO, 2004, p. 14-15).

Fomentar atos discriminatórios por meio de políticas de assimilação, segregação e não reconhecimento de minorias é uma forma de impedir que as pessoas possam exercer seus direitos de forma igual, com as mesmas oportunidades de escolha, resultando não só na diminuição do crescimento econômico, como também em patente violação e desrespeito da dignidade humana, da liberdade e da democracia, podendo resultar, segundo Vital Moreira e Carla Marcelino Gomes, ainda no incentivo de conflitos sociais e civis entre as pessoas e comunidades (MOREIRA; GOMES, online). 
No contexto de grupos minoritários, a discriminação poderia se constituir como um fator comum na busca pelo reconhecimento de direitos e da sua própria identidade e culturas, na medida em que se tem que esta aparece como um sentimento comum desses grupos, os quais, em algum momento do caminhar da sua história, do desenvolvimento da sua identidade e dos seus direitos, vivenciaram e ainda vivenciam episódios de exclusão, segregação, extermínio e preconceitos.

As pessoas com deficiência, por exemplo, passaram por fases de extrema negação de direitos e segregação social, objetivando-se, num desses períodos, curá-las e torná-las o mais normal possível dentro do considerado padrão comum. Os negros foram colonizados e subordinados a prestar trabalho escravo e na África foram submetidos ao regime do apartheid. Os surdos tiverem que se sujeitar a uma cultura ouvinte majoritária e dominante, sendo-lhes proibido a aprendizagem e o uso da linguagem de sinais (SKLIAR, 2015, p. 17). As mulheres somente conquistaram direito de voto, no Brasil, em 1932 (82 anos, online).

Todos esses grupos minoritários, cada um com as suas particularidades e história, possuem um ponto em comum: de algum modo e em certo grau sofreram ou ainda sofrem discriminação diante de suas diferenças, em razão do desconhecimento da sociedade como um todo de suas capacidades e potencialidades.

Com efeito, atento as realidades destes grupos, especialmente aquelas em que a vida humana restou quase reduzida a condição de objeto ou de coisa, os diplomas internacionais preconizaram o mandamento da não discriminação, segundo o qual a discriminação, nos termos adotados pela maioria dos documentos internacionais, passa a ser compreendida como todo ato de distinção, exclusão, restrição ou preferência, cujo efeito resultasse na anulação ou prejudicasse o reconhecimento, o usufruto e o exercício dos direitos humanos de forma igualitária nas esferas políticas, econômica, social ou cultural ou qualquer outro âmbito (SHELTON, online).

O tratamento discriminatório restaria configurado, portanto, quando desprovido de justificação razoável, proporcionalidade ou, de fato, seja prejudicial para a pessoa. Conforme destaca Dinah Shelton, “[...] no todo trato diferenciado equivale a discriminación, sino sólo el que no es razonable, es injustificado y prejudicial para la persona" (SHELTON, online). Somente deve se rechaçar, assim, "[...] las clasificaciones fundamentadas en supuestas características de grupo o las estereotipadas no están permitidas” (SHELTON, online). 
Nesse sentido, o Pacto Internacional dos Direitos Econômicos, Sociais e Culturais elencou rol de natureza meramente exemplificativa de motivos e condutas proibidas, as quais mesmo que praticadas de forma indireta serão consideradas discriminatórias. A Convenção Internacional sobre os Direitos das Pessoas com Deficiência, por sua vez, cuidou da questão da igualdade e da não discriminação de pessoas com deficiência em razão da deficiência, reconhecendo-se, assim, a necessidade de promoção e proteção de todo direito humano das pessoas com deficiência (SHELTON, online).

Dessa forma, a igualdade e o mandamento de não discriminação estão, conforme destaca Shelton, implícitos nos diplomas que preconizam a proteção dos direitos humanos, podendo ser considerados o direito mais fundamental ou mesmo como o ponto de partida das demais liberdades (SHELTON, online).

Com efeito, poder-se-ia classificar o mandamento de não discriminação como um critério objetivo mínimo para a definição de minorias.

\subsection{A igualdade material redimensionada pela diferença como critério subjetivo mínimo}

A igualdade pode ser vista, nos moldes delineados por Flávia Piovesan em três perspectivas ou redimensionamentos: a igualdade formal ou perante a lei, a igualdade substancial ou material e a igualdade material enquanto reconhece identidades.

\footnotetext{
Destacam-se, assim, três vertentes no que tange à concepção de igualdade: a) igualdade formal, reduzida à formula "todos são iguais perante a lei" (que, ao seu tempo, foi crucial para a abolição de privilégios); b) igualdade material, correspondente ao ideal de justiça social e distributiva (igualdade orientada pelo critério socioeconômico); e c) a igualdade material, correspondente ao ideal de justiça enquanto reconhecimento de identidades (igualdade orientada pelos critérios de gênero, orientação sexual, idade, raça, etnia e demais critérios). (PIOVESAN, 2009, p. 49).
}

A igualdade formal prevista no artigo $5^{\circ}$, caput, da Constituição Federal de 1988, além de elevar à condição de direito fundamental o princípio da igualdade, dispõe que "todos são iguais perante a lei, sem distinção de qualquer natureza". 
Nessa linha, seria inconstitucional e contrário aos fundamentos maiores da Constituição brasileira a discriminação sofrida por determinados grupos, preconizando-se, assim, o ideal de inclusão sem distinções de quaisquer natureza, seja pessoa com deficiência, seja portador de HIV, seja mulher, homossexual ou integrante de outro grupo minoritário.

Não obstante a proteção formal da lei, que teve a sua relevância no momento histórico no qual se promulgou a Constituição Federal de 1988, seria necessário o redimensionamento da igualdade numa concepção material, isto é, não basta que "o ordenamento jurídico trate todos os cidadãos isonomicamente, sem quaisquer distinções" (QUARESMA, 2001, p. 03), mas deve haver a igualdade fática ou real. Não basta estar no papel, deve ser real do ponto de vista social, pois "é preciso tratar os iguais com igualdade e os desiguais desigualmente, na exata medida de sua desigualdade" (QUARESMA, 2001, p. 04).

O direito à igualdade, portanto, vai além do tratamento igual para todos na forma da lei, consistente na igualdade formal ou perante a lei, abrangendo, também, o direito à diferença, isto é, a igualdade material cujo redimensionamento importa no reconhecimento de identidades e da diversidade cultural e humana.

Nesse sentido, o Comitê dos Direitos Econômicos, Sociais e Culturais, em sua Recomendação Geral no 16 tracejou definição acerca da igualdade formal e da igualdade em seu aspecto material ou substantiva, adotando, ao final, a prevalência desta, no contexto da igualdade de gênero, uma vez que não é o simples fato de editar leis ou adotar políticas estatais que se estará efetivando igualdade de fato (COMMITTE ON ECONOMIC, SOCIAL AND CULTURAL RIGHTS, 2005 apud PIOVESAN, 2008, p. 55-56).

Reconhece-se que a igualdade formal, outrora festejada quando da mudança do regime ditatorial para o democrático, não é mais suficiente na ordem jurídica constitucional. Se, naquele momento, a igualdade formal foi importante propulsor do Estado Democrático de Direito, atualmente a igualdade necessita ser analisada num contexto diferenciado.

Portanto, nos moldes delineados por Flávia Piovesan, antes da adoção da igualdade perante a lei, a diferença existente em cada pessoa era o fator principal para o extermínio, a justificativa para a negativa de direitos humanos e fundamentais (PIOVESAN, 2008, p. 49). Nasce nesse momento, a par do direito à igualdade, o direito à diferença, "como um redimensionamento do direito à igualdade" (NÓBREGA; JOCA, online). 
No presente momento histórico, não se pode conceber a efetivação de direitos humanos e fundamentais sem a aplicação da igualdade no seu sentido material, bem como a aceitação - diante do reconhecimento da existência de minorias e, consequentemente, da necessidade de proteger os direitos inerentes a esse grupo -, da aplicabilidade do direito à diferença, considerado, nesta linha, como um redimensionamento da igualdade material.

Dessa forma, além do direito à igualdade em seu sentido material, é necessário reconhecer o direito à diferença como diretriz que possa viabilizar a concretização de condições melhores para os grupos minoritários, de modo, como dispõe Flávia Piovesan, a atentar para a “especificação do sujeito de direito" (PIOVESAN, 2008, p. 49), ou seja, para a proteção das particularidades do indivíduo, a fim de proporcionar-lhe tratamento adequado e em conformidade com a sua diferença. Nesse sentido, concebe-se o direito à diferença como um direito fundamental ao lado do direito à igualdade, importando no "[...] respeito à diferença e à diversidade, o que lhes assegura um tratamento especial" (PIOVESAN, online).

Justamente por serem criaturas livres, os homens devem se submeter ao mesmo tratamento. Todavia, como a igualdade consiste igualmente num conceito relativo, não se pode falar de uma igualdade absoluta, cujos preceitos equivaleriam para todos.

Deve-se levar em consideração, assim, um critério de diferença a fim de se determinar como devem ser formuladas e desenvolvidas as diversas políticas públicas, atentando para as condições especiais das diferentes minorias. Atentar para a diferença poderia promover a superação de paradigmas e preconceitos petrificados na sociedade como discriminantes, negativos ou inferiores, substituindo-o, assim, por padrões igualitários e justos, evitando também possíveis conflitos civis.

Com efeito, tem-se que a igualdade material redimensionada pela diferença é um importante critério mínimo para a definição de minorias, na medida em que se objetiva evitar a adoção e prática de políticas de exclusão, segregação ou assimilação, mas preconizar os ideais de inclusão e reconhecimento de identidades com base na implementação de práticas educacionais igualitárias que proporcionem iguais condições de acesso a oportunidades e a liberdade de participação para todos, sem distinções de qualquer natureza.

As minorias seriam, então, identificadas segundo essa diferença, ou seja, em razão daquela condição que as destacaria dos demais, do todo, de tal forma a chamar para si, diante do contexto em que estiverem inseridas, a proteção dos direitos das minorias. 


\section{AS PESSOAS COM DEFICIÊNCIA COMO MINORIAS}

Por fim, indaga-se se as pessoas com deficiência podem ser consideradas minorias. Para tanto, num primeiro momento, será explicada, nos moldes do critério objetivo mínimo escolhido, algumas fases da história das pessoas com deficiência na busca do reconhecimento de direitos e da própria identidade como sujeito de direitos e pessoa humana para destacar processos discriminatórios pelos quais este grupo perpassou.

As pessoas com deficiência passaram por intensa luta histórica rumo ao seu reconhecimento como pessoa humana, para a consideração de sua identidade e a formulação e edição de políticas para a proteção de seus direitos. Lutiana Nacur Lorentz classifica essas fases em fase de eliminação, fase do assistencialismo, fase de integração e fase de inclusão (LORENTZ, 2006, p. 194-197).

A fase de eliminação (LORENTZ, 2006, p. 194) consiste na exclusão de pessoas com deficiência, caracterizando-as como não humanos. A presença do estigma é o fator determinante, não havendo qualquer proteção ou comoção social para com essas pessoas. A pessoa com deficiência era considerada um ser inútil e absolutamente incapaz.

Na fase do assistencialismo (LORENTZ, 2006, p. 195), verifica-se a tolerância da sociedade em relação às pessoas com deficiência, substituindo-se, assim, algumas nomenclaturas pejorativas, para adotar outras nas quais havia a diminuição da pessoa ao status de uma criança. Destinava-se às pessoas com deficiência um olhar de pena, não obstante ainda houvesse a sua rejeição, ocorrendo de a proteção jurídica habitual se destinar somente às pessoas sem deficiência.

Há que se falar, propriamente, em duas subfases dentro desta etapa. A primeira se dá com o advento do Cristianismo e com a vinda de Jesus Cristo, elevando o homem a imagem e semelhança de Deus. Conforme preleciona Aranha: "Com o advento do Cristianismo, a situação se modificou, pois todos passaram a ser igualmente considerados filhos de Deus, possuidores de uma alma e, portanto merecedores do respeito à vida e a um tratamento caridoso" (ARANHA, 2001, p. 161).

Nesse sentido, contrariando os costumes que se tinha naquela época, Jesus Cristo curou o leproso, considerado e tratado como uma "aberração", o qual era, inclusive, relegado ao 
exílio, afastado de toda a sociedade. No primeiro capítulo do Evangelho de Marcos, observase, assim, o tratamento igualitário e caridoso do Filho de Deus para com o doente, tratando-o sem sentir repulsa, mas dele compadecendo e concedendo-lhe misericórdia (BÍBLIA SAGRADA. Marcos, 1; 40-45).

O tratamento bondoso e caridoso destinado a essas pessoas perdurou até a Reforma da Igreja e a sua consequente segregação após a determinação papal de condená-los a diversos castigos, iniciando-se aqui a segunda subfase do assistencialismo (ARANHA, 2001, p. 163). A deficiência era concebida como "[...] fenômenos metafísicos, de natureza negativa, ligados à rejeição de Deus, através do pecado, ou a possessão demoníaca" (ARANHA, 2001, p. 163). Diversos tratamentos desumanos lhes eram destinados a fim de que se extinguisse o mal que havia dentro da pessoa. Iniciou-se aqui a "caça e exterminação dos que passou a chamar hereges e endemoniados" (ARANHA, 2001, p. 162).

Já na fase de integração (LORENTZ, 2006, p. 195-196) a maioria se posicionou no sentido de que a pessoa com deficiência deveria ser consertada para depois ser integrada como uma pessoa normal em sociedade. Poder-se-ia dizer que se trata, na verdade, da fase da medicação. Descobrir, diagnosticar e tratar consistiam nos principais objetivos da sociedade.

Uma das manifestações da fase da medicação e normalização pode ser explicada com a tentativa de ensinar surdos congênitos a comunicar pela via oral, proibindo-se o uso da linguagem de sinais, tentativa que não restou bem sucedida, segundo destaca Aranha (ARANHA, 2001, p. 164).

O que os médicos propuseram para a cura de certas deficiências, resultaria na segregação do convívio social por longos períodos de tempo. Enclausurar estas pessoas era a solução para diversos problemas, mas não o principal deles, destinar-lhe tratamento humano, inclui-las e tentar, ao menos reduzir a discriminação por elas sofrida. Os médicos passaram, assim, a reger a vida das pessoas com deficiência, buscando curá-las de suas enfermidades, sendo a deficiência considerada um problema unicamente da pessoa. Os médicos se transformam, segundo leciona Agustina Palácios, nos grandes atores deste modelo ou desta fase (PALÁCIOS, 2008, p. 99).

Todavia, percebia-se a formação de pessoas cuja dependência se tornava quase que infantil, havendo, na verdade, o agravamento do seu quadro, de forma que ela adquiria um novo "sintoma" ou "deficiência", qual seja, a enfermidade mental, as psicoses, como “[...] baixa auto- 
estima, ausência de motivação para a vida, desamparo aprendido e distúrbios sexuais" (ARANHA, 2001, p. 166).

Nesse sentido, surgiram várias doutrinas que buscavam a integração da pessoa com deficiência através do fim da institucionalização, tornando-a o mais normal possível dentro dos padrões adotados pela maioria da sociedade, configurando a fase de integração. Contudo, esta fase não perdurou por muito tempo, pois não atingia o objetivo principal: reconhecer a identidade da pessoa com deficiência, reconhecer que a deficiência não está na pessoa, mas nas barreiras que lhe são impostas pela sociedade, pela discriminação histórica a que estiveram submetidas no decorrer do tempo.

Com o enfraquecimento do paradigma do serviço (ARANHA, 2001, p. 168-169), o qual buscava a integração da pessoa com deficiência através da sua normalização, surge o paradigma de suporte (ARANHA, 2001, p. 170), responsável pela inclusão da pessoa com deficiência, independentemente de grau de "normalidade". Objetivava-se, assim, garantir o amplo acesso, independentemente de qualquer grau de "normalidade".

Trata-se, propriamente, da fase de inclusão social (LORENTZ, 2006, p. 195-197) da pessoa com deficiência, no qual se buscou formular um “[...] ajuste mútuo, onde cabe a pessoa com deficiência manifestar-se com relação aos seus desejos e necessidades e à sociedade, a implementação dos ajustes e providências necessárias que a ela possibilitem o acesso e a convivência no espaço comum, não segregado" (ARANHA, 2001, p. 171).

Diferencia-se, assim, a integração de inclusão. A integração se focaliza na modificação do sujeito de modo que este possa ser o mais normal possível, enquanto a inclusão prevê intervenções tanto no desenvolvimento do sujeito quanto no reajuste da realidade social, no sentido de promover os mecanismos necessários para aquisição de acessibilidade mais célere ao espaço comum na sociedade (ARANHA, 2001, p. 171).

Nos dias atuais, predomina a fase da inclusão, com o desenvolvimento de novos paradigmas de educação inclusiva, de reconhecimento formal de direitos, da promoção da identidade, da cultura e da diferença das pessoas com deficiência, incidindo, assim, no critério subjetivo da igualdade material redimensionada pela diferença.

As pessoas com deficiência são caracterizadas como minorias, pois possuem uma condição que as individualizam em relação às demais pessoas, devendo ser protegidas em conformidade com esse fator. 
No embalo do reconhecimento da pessoa com deficiência como sujeito de direitos e em conformidade com o modelo de inclusão delineado nas premissas de proteção dos direitos humanos, alguns diplomas normativos foram essenciais para tal desiderato, sendo a Convenção Internacional sobre os Direitos da Pessoa com Deficiência um deles.

Levou-se a cabo neste diploma internacional, entre outros princípios de importância fundamental para o desenvolvimento e reconhecimento dos direitos das pessoas com deficiência, o mandamento da não discriminação e da igualdade, estabelecendo-se, assim, mecanismos e medidas pelos quais a pessoa com deficiência pudesse se estabelecer em sociedade como sujeito de direitos e detentor de capacidade jurídica no sentido de poder tomar decisões de forma autônoma e de se determinar como pessoa que possui direitos e obrigações perante a sociedade.

À luz da Convenção Internacional sobre os Direitos da Pessoa com Deficiência, o Estado brasileiro fez editar e promulgar o Estatuto da Pessoa com Deficiência ou, também denominada, Lei Brasileira de Inclusão (Lei $\mathrm{n}^{\circ}$ 13.146/2015), a qual, seguindo a linha do diploma internacional citado, buscou reconhecer a capacidade jurídica da pessoa com deficiência como sujeito de direitos.

A Lei Brasileira de Inclusão destinou várias medidas a serem implementadas em todo o território brasileiro cuja finalidade precípua seja a inclusão da pessoa com deficiência em todos os setores da sociedade - educação, saúde, política e trabalho, sem distinções de qualquer espécie, além de promover o amplo acesso a liberdades substantivas, preconizando-se a participação plural desse grupo, a fim de promover uma sociedade justa, democrática, plural e igualitária.

Nesse sentido, o Supremo Tribunal Federal realizou recentemente o julgamento da ADI 5357, no qual determinou, na linha do mandamento da não discriminação, da igualdade e do respeito à diferença, a extensão das premissas preconizadas pela Lei Brasileira de Inclusão no que tange à educação destinada às pessoas com deficiência às escolas privadas, as quais devem segui-los sem repassar os custos financeiros ou econômicos para as mensalidades dos alunos ou a cobrança de taxas extras pela prestação do serviço (BRASÍLIA. Supremo Tribunal Federal, 2016). 
EMENTA: AÇÃO DIRETA DE INCONSTITUCIONALIDADE. MEDIDA CAUTELAR. LEI 13.146/2015. ESTATUTO DA PESSOA COM DEFICIÊNCIA. ENSINO INCLUSIVO. CONVENÇÃO INTERNACIONAL SOBRE OS DIREITOS DAS PESSOAS COM DEFICIÊNCIA. INDEFERIMENTO DA MEDIDA CAUTELAR. CONSTITUCIONALIDADE DA LEI 13.146/2015 (arts. $28, \S^{\circ}{ }^{\circ}$ e 30, caput, da Lei $\mathrm{n}^{\circ}$ 13.146/2015).

1. A Convenção Internacional sobre os Direitos da Pessoa com Deficiência concretiza o princípio da igualdade como fundamento de uma sociedade democrática que respeita a dignidade humana.

2. À luz da Convenção e, por consequência, da própria Constituição da República, o ensino inclusivo em todos os níveis de educação não é realidade estranha ao ordenamento jurídico pátrio, mas sim imperativo que se põe mediante regra explícita. 3. Nessa toada, a Constituição da República prevê em diversos dispositivos a proteção da pessoa com deficiência, conforme se verifica nos artigos $7^{\circ}$, XXXI, 23, II, 24, XIV, 37, VIII, 40, $\S 4^{\circ}$, I, 201, $\S 1^{\circ}, 203$, IV e V, 208, III, 227, § $1^{\circ}$, II, e $\S 2^{\circ}$, e 244.

4. Pluralidade e igualdade são duas faces da mesma moeda. $\mathrm{O}$ respeito à pluralidade não prescinde do respeito ao princípio da igualdade. E na atual quadra histórica, uma leitura focada tão somente em seu aspecto formal não satisfaz a completude que exige o princípio. Assim, a igualdade não se esgota com a previsão normativa de acesso igualitário a bens jurídicos, mas engloba também a previsão normativa de medidas que efetivamente possibilitem tal acesso e sua efetivação concreta.

5. O enclausuramento em face do diferente furta o colorido da vivência cotidiana, privando-nos da estupefação diante do que se coloca como novo, como diferente.

6. É somente com o convívio com a diferença e com o seu necessário acolhimento que pode haver a construção de uma sociedade livre, justa e solidária, em que o bem de todos seja promovido sem preconceitos de origem, raça, sexo, cor, idade e quaisquer outras formas de discriminação

(Art. $3^{\circ}$, I e IV, CRFB).

7. A Lei $\mathrm{n}^{\circ} 13.146 / 2015$ indica assumir o compromisso ético de acolhimento e pluralidade democrática adotados pela Constituição ao exigir que não apenas as escolas públicas, mas também as particulares deverão pautar sua atuação educacional a partir de todas as facetas e potencialidades que o direito fundamental à educação possui e que são densificadas em seu Capítulo IV.

8. Medida cautelar indeferida.

9. Conversão do julgamento do referendo do indeferimento da cautelar, por unanimidade, em julgamento definitivo de mérito, julgando, por maioria e nos termos do Voto do Min. Relator Edson Fachin, improcedente a presente ação direta de inconstitucionalidade. (BRASÍLIA, Supremo Tribunal Federal, 2016).

Dessa forma, atentando-se para as suas particularidades, as pessoas com deficiência gozam das prerrogativas destinadas aos demais grupos de minorias, devendo, assim ser caracterizadas, uma vez que são socialmente vulneráveis, ainda sofrendo em consequência de atos discriminatórios, carecendo-se, assim, de medidas de proteção especializada, apta a reconhecer e efetivar direitos inerentes a sua condição.

Portanto, pessoas com deficiência podem ser classificadas, nos moldes dos critérios propostos no presente trabalho, como grupos minoritários, gozando, assim, da proteção inerente ao direito das minorias. 


\section{CONSIDERAÇÕES FINAIS}

Não seria possível adotar uma definição absoluta e estanque sobre quem seriam as minorias. Também seria, de igual forma, impossível fixar um rol de grupos minoritários, fetichizando uma classificação de quem seria minoria ou não e, via de consequência, de quem gozaria ou não da proteção destinada a esses grupos.

A dinamicidade da vida social não permite que se adote uma definição que leve em consideração somente critérios objetivos e nem permite que se realize a ampla abertura destes, adotando-se critérios puramente subjetivos, na medida em que se abriria margem para a prática de excessos, abusos e fraudes por parte de quem não se encaixaria propriamente nos grupos minoritários.

Com efeito, busca-se um conceito de minorias que atinja um ponto ótimo de equilíbrio entre critérios objetivos e subjetivos, ou seja, um ponto comum em que fosse possível proteger e assegurar direitos, além de permitir a abertura para grupos que pudessem vir a ser considerados como tal posteriormente.

Desta feita, propôs-se a utilização da discriminação como critério objetivo mínimo, uma vez que, em alguma medida e em determinado grau, os indivíduos pertencentes a grupos minoritários já passaram ou ainda sofrem em decorrência de situações vexatórias ou foram diminuídos a condições não humanas.

O critério subjetivo mínimo consistiria na igualdade redimensionada pela diferença com o objetivo de reconhecer identidades e promover a justiça social para reduzir os efeitos da discriminação, possibilitando-se, assim, iguais oportunidades de acesso e exercício de liberdades, influenciando, consequentemente, no desenvolvimento da sociedade como um todo. As minorias seriam identificadas por meio dessa característica diferenciante, realizando-se a especificação do sujeito que compõe determinado grupo minoritário, nos moldes explicitados por Piovesan, de modo a chamar para si a proteção específica inerente aos direitos das minorias.

Por fim, conclui-se que as pessoas com deficiência são grupos minoritários diante do histórico de discriminação vivenciado por este grupo na busca do reconhecimento de sua identidade, bem como dos seus direitos, além de carecerem, de certo modo e grau, de proteção 
especializada, apta a efetivar direitos humanos e fundamentais em conformidade com a sua condição diferenciadora, necessitando, nesta linha, de igual forma, da especificação da tutela jurisdicional dos direitos das minorias.

\section{REFERÊNCIAS BIBLIOGRÁFICAS}

ARANHA, Maria Salete Fábio. Paradigmas da relação da sociedade com as pessoas com deficiência. Revista do Ministério Público do Trabalho, Brasília, ano XI, n. 21, p. 160-173, mar.2001.

BÍBLIA SAGRADA. Marcos, 1; 40-45.

BOBBIO, Noberto. Elogio da serenidade e outros escritos morais. São Paulo: Unesp, 2002.

BRASIL. Constituição da República Federativa do Brasil de 1988. Disponível em: < http://www.planalto.gov.br/ccivil_03/constituicao/constituicao.htm>. Acesso em 04 jan. 2018.

Decreto $\mathbf{n}^{\mathbf{0}}$ 591, de 6 de julho de 1992. Atos Internacionais, Pacto Internacional sobre Direitos Econômicos, Sociais e Culturais. Promulgação. 1992. Disponível em: < http://www.planalto.gov.br/ccivil_03/decreto/1990-1994/d0591.htm>. Acesso em: 04 jan. 2018.

Decreto $\mathbf{n}^{0}$ 592, de 6 de julho de 1992. Atos Internacionais, Pacto Internacional dos Direitos Civis e Políticos, Promulgação. 1992. Disponível em: < http://www.planalto.gov.br/ccivil_03/decreto/1990-1994/d0592.htm>. Acesso em 04 jan. 2018.

. Decreto no 6949, de 25 de agosto de 2009. Promulga a Convenção Internacional sobre os Direitos das Pessoas com Deficiência e seu Protocolo Facultativo, assinados em Noiva Iorque, em 30 de março de 2007. 2009. Disponível em: < http://www.planalto.gov.br/ccivil_03/_ato2007-2010/2009/decreto/d6949.htm>. Acesso em: 04 jan. 2018.

Lei $\mathbf{n}^{\mathbf{0}}$ 13.146, de 6 de julho de 2015. Institui a Lei Brasileira de Inclusão da Pessoa com Deficiência (Estatuto da Pessoa com Deficiência). 2015. Disponível em: < http://www.planalto.gov.br/ccivil_03/_ato20152018/2015/lei/l13146.htm>. Acesso em: 04 jan. 2018.

BRITO FILHO, José Claudio Monteiro. Direitos humanos, cidadania, trabalho. José Claudio Monteiro de Brito Filho: Belém, 2004.

LORENTZ, Lutiana Nacur. A norma da igualdade e o trabalho das pessoas portadoras de deficiência. São Paulo: LTr, 2006. 
MOREIRA, Vital; GOMES, Carla Marcelino (Coord.). Compreender os Direitos Humanos: manual de educação para os direitos humanos. In: Universidade de Coimbra. Disponível em: < http://www.fd.uc.pt/igc/manual/pdfs/manual_completo.pdf>. Acesso em: 30 jun. 2017.

MORENO, Jamile Coelho. Conceito de minorias e discriminação. Revista USCS de Direito, São Caetano do Sul, ano X, n. 17, p. 141-156, jul./dez. 2009.

NÓBREGA, Luciana Nogueira; JOCA, Priscylla. Direito das minorias à luz do direito fundamental à igualdade. XVIII COGRESSO NACIONAL DO CONPEDI, 2009, São Paulo. Anais eletrônicos. Florianópolis: Fundação Boiteaux, 2009. Disponível em: $<$ https://s3.amazonaws.com/conpedi2/anteriores/XVIII+Congresso+Nacional+-+FMU-

$\mathrm{S} \% \mathrm{C} 3 \% \mathrm{~A} 3 \mathrm{o}+\mathrm{Paulo}+(04 \% 2 \mathrm{C}+05 \% 2 \mathrm{C}+06+\mathrm{e}+07+\mathrm{de}+$ novembro+de+2009).pdf $>$. Acesso em: 30 jun. 2017.

PALACIOS, Agustina. El modelo social de discapacidad: Orígenes, caracterización y plasmación en la Convención Internacional sobre los Derechos de las Personas con Discapacidad. Madrid: Comité Español de Personas com Discapacidad y Ediciones Cinca, 2008.

PIOVESAN, Flávia. Igualdade, diferença e direitos humanos: perspectivas global e regional. In: SARMENTO, Daniel; IKAWA, Daniela; PIOVESAN, Flávia (Coord.) Igualdade, diferença e direitos humanos. Rio de Janeiro: Lumen Juris, 2008.

Ações afirmativas da perspectiva dos direitos humanos. Cad. Pesqui., São Paulo, v. 35, n. 124, Apr. 2005 . Disponível em: <http://www.scielo.br/scielo.php?script=sci_arttext\&pid=S010015742005000100004\&lng=en \&nrm=iso>. Acesso em: 30 jun. 2017.

QUARESMA, Regina. Comentários à legislação constitucional aplicável às pessoas portadoras de deficiências. In: TEPERINO, Maria Paula (Coord.). Comentários à legislação federal aplicável às pessoas portadoras de deficiência. Rio de Janeiro: Forense, 2001.

RIOS JÚNIOR, Carlos Alberto dos. Direito das minorias e limites jurídicos ao poder constituinte originário. São Paulo: Edipro, 2012.

ROCHA, Carmen Lúcia Antunes. Ação afirmativa: o conteúdo democrático do princípio da igualdade jurídica. Revista de informação legislativa, v. 33, n. 131, p. 283-295, jul./set. 1996.

ROTHENBURG, Walter Claudius. Direitos dos descendentes de escravos (remanescentes das comunidades de quilombos). In: IKAWA, Daniela; PIOVESAN, Flávia; SARMENTO, Daniel. Igualdade, Diferença e Direitos Humanos. Rio de Janeiro: Lúmen Juris, 2010.

SEMPRINI, Andrea. Multiculturalismo. Tradução Laureano Pelegrin. São Paulo: EDUSC, 1999. 
SHELTON, Dinah. Prohibición de Discriminación en el Derecho Internacional de los Derechos Humanos. In: Portal de Revistas Académicas de la Universidad del Chile. Disponível em: <http://www.revistas.uchile.cl/index.php/ADH/article/viewFile/13488/13756>. Acesso em 09 ago. 2017.

SKLIAR, Carlos. Os estudos surdos em educação: problematizando a normalidade. In: SKLIAR, Carlos (Org.). A surdez: um olhar sobre as diferenças. 7. ed. Porto Alegre: Mediação, 2015.

STF, ADI 5357/DF, Rel. Ministro Edson Fachin, julgado em 09.06.2016, DJE no 240 de 11.11.2016, divulgado em 10.11.2016.

THORNBERRY, Patrick. Minorities and Human Rights Law: a minority rights group report. British Library, 1991.

WUCHER, Gabi. Minorias: proteção internacional em prol da democracia. São Paulo: Editora Juarez Oliveira, 2000.

82 anos de conquista do voto feminino no Brasil. In: Tribunal Regional Eleitoral do Espírito Santo. Disponível em: <http://www.tre-es.jus.br/imprensa/noticias-tre-es/2014/Fevereiro/82anos-da-conquista-do-voto-feminino-no-brasil>. Acesso em: 30 jun. 2017. 